\title{
How Stephen Jay Gould wrote Macbeth-Not giving credit where it's due: lazy referencing and ignoring precedence
}

\author{
Simon R. Leather \\ Simon R. Leather (simonleather@harper-adams.ac.uk), Crop \& Environment Sciences, Harper Adams University, \\ Edgmond, Newport UK TF10 8NB
}

In responding to Bruun's (2014) very interesting article, I have taken the liberty of plagiarising a title I have previously used in a blog post (Leather 2013). Although I do not entirely agree with Bruuns' thesis, I found it a very enjoyable read. I would point out however, that the title is somewhat misleading as most of the paper does not deal with plagiarism per se.

Bruun (2014) deals with three linked ideas: first, that too much reference trawling, sensu Leather (2004), will stifle innovation and creativity; second, what defines originality; and third, the concept that ownership of ideas is egocentric and harmful to the progress of science.

I am absolutely and totally in agreement with the sentiments presented in the first paragraph of Bruun's paper in which he condemns plagiarism and also those researchers that consciously present an idea or data as novel or original when it is not. In this context I also agree with Bruun that-although annoying for the authors with a primary claim on the idea or conceptunconscious or a subconscious failure to cite the original is not fraud. Fraud implies a deliberate act on the behalf of the perpetuator; laziness or carelessness, although to be deplored, is not a fraud.

As presumably one of the "grumpy, old-fashioned scholars" who referees and edits journals (Bruun 2014: 34), I think that it is entirely justifiable to reject a manuscript that claims total originality when a more indepth review of the literature would reveal the existence of similar, if not identical work. I would however, not reject a good piece of work that although not entirely original in concept, adds new data and interpretation to an old idea, so long as the original is not ignored.

Bruun (2014) suggests that by carefully searching out original sources we run the risk of becoming archaeologists. Is there anything wrong with being an archaeologist in the literature? Historians and archaeologists both find new interpretations and discoveries by re-examining old documents and re-digging old sites. I recently undertook a similar quest to find the original source to an undocumented 'fact' I was told as an undergraduate and had used myself for many years in teaching without checking its veracity. The journey of discovery was rewarding and illuminating, the full story of which can be found at my blog (Leather 2013).

Bruun (2014) suggests that new ideas are born with some difficulty in that they are outside recognized theory (Pickett et al. 1994) and that they need a famous and influential advocate to act as a 'midwife' who then becomes the most cited proponent of the concept to the detriment of the original author. There are some elements of truth in this, but I think it is more to do with referees and editors who may be, in the words of the following paragraph, egocentric and anxious to retain ownership of the 'old' idea rather than being, as all scientists should, open minded and receptive to new ideas. I agree with Bruun that people are more likely to cite the famous 'prophet' that raised the profile of the original new concept/idea but that does not justify it - it is once again the fault of shallow reference trawling as pointed out ten years ago (Leather 2004) and raised more recently in a blog post (Leather 2013).

Bruun (2014) suggests that deep reference trawling will effectively halt innovative and clear ideas. I could be pedantic and respond by saying that if it has already been described by someone else, even if it has not been cited by the 'new' author, then it is surely not innovative? That said, I have on numerous occasions when looking for old references come across unrelated papers in the journals I was searching through and had my viewpoint changed and gained new ideas for research. By looking at the preliminary data and proto- 
ideas, with the perspective of modern thinking and extra information available, one often comes up with new viewpoints or directions for future research. Bruun (2014) also suggests that retesting a 'novel' idea in another context will halt the advance of science. I am at a loss to see why this is so. We are taught as scientists that our experiments should be replicated, so why are we wrong to corroborate or test ideas? Surely this is just replication, which is a good thing? The idea that an experiment only needs to be done once is an unfortunate fallacy that science, not just ecology, seems to have adopted in recent years. We need only look at medical science to see what happens if work is not repeated and tested.

Linked with this is the habit some authors in recent years have adopted: namely, inappropriate citation of authors in relation to discovery of a particular fact. So for example, suppose an author writing a paper about barley infestation by cereal aphids wants to support his/ her arguments by saying that barley is probably more susceptible to aphid attack because, as it grows quickly, there is a trade off in respect to reduced plant defences. Instead of going to a primary source, the author remembers reading in another paper-for sake of this argument, a paper by Rowntree et al. (2010) studying growth of the grain aphid Sitobion avenae on barleywhere those authors in their discussion mention that barley is probably poorly defended against herbivory, in turn citing Coley et al. (1985). Our fictional author in his/her paper, now states, "in my experiment, barley plants were more susceptible to aphid attack than the slower growing grass, Festuca ovina, probably because plant resistance against herbivory in barley, was reduced due to the trade off between rapid growth and defensive chemistry (Rowntree et al., 2010)." This is, of course, a totally inappropriate citation, because a) Rowntree and colleagues did not report any such data and b) the paper by Coley et al., did not deal with barley. We thus have a totally erroneous chain of citations. In this case I have invented the whole scenario. I can assure you however, that as an editor, referee, and reader, I have come across similar erroneous citation chains on many occasions in the recent past, and not just in undergraduate student project reports or $\mathrm{MSc}$ and $\mathrm{PhD}$ theses. This does not do science any favours, nor does it give credit where it is due.

I am in total agreement with Bruun's final point. I feel that in the interests of science we should all be willing to share ideas and, rather than sitting on ideas that I hope I might have time to follow up, I often suggest to colleagues that they might like to take the lead on them; life is too short to do everything and as long I get an acknowledgement, I am happy. Yes, any use of the idea should be either acknowledged, if it has not been published, and if it has been published then it should be cited in full. As referees and journal editors, we should be receptive to new ideas and, if the idea comes with a proper experimental design and appropriate statistics to back it up, then even if we disagree with it we should not block its publication. I have as a referee had a number of papers where I have not 'believed' the finding or they have contradicted my ideas, but as the science was conducted well and the experimental design sound, I felt that despite my 'beliefs' (and as an open-minded scientist I am not sure that we should have beliefs or convictions), I recommended publication.

And finally, to shamelessly plagiarise myself (Leather 2013): how could Stephen Jay Gould have written Macbeth, which I am sure you all know is actually by William Shakespeare. Well, in an essay entitled Dinomania in Dinosaur in a Haystack (Gould 1996), Gould quotes the first line of Macbeth's soliloquy, "If it were done, "twere well it were done quickly." Now, whilst no scientist, or I hope any scholar, would state in a piece of work, something like "Macbeth wondered if he should kill King Duncan (Gould 1996)", many authors seem to have no problems with doing exactly the same sort of thing in their introductions or discussions in scientific papers. Please, please, check your sources and give credit where it's due.

\section{References}

Bruun, H.H. 2014. Zero tolerance to plagiarism will kill inspiration: a critique for academic meritocracy. Ideas in Ecology and Evolution 7:34-37. CrossRef

Coley, P.D., Bryant, J.P. and F.S. Chapin. 1985. Resource availability and plant herbivore defense. Science 230: 895-899. CrossRef

Gould, S.J. 1996. Dinosaur in a Haystack, Jonathan Cape, London.

Leather, S.R. 2004. Reinventing the wheel: on the dangers of taxon parochialism and shallow reference trawling. Basic \& Applied Ecology 5: 309-311. CrossRef

Leather, S.R. 2013. How Stephen Jay Gould wrote Macbeth: not giving credit where it's due, lazy referencing and ignoring precedence. Posted March 28 2013, http://simonleather.wordpress.com/2013/03/28 /how-stephen-jay-gould-wrote-macbeth-not-givingcredit-where-its-due-lazy-referencing-and-ignoringprecedence/

Leather, S.R. 2013. Desperately seeking sources: the quest for the original citation. Posted June 62013 , http://simonleather.wordpress.com/2013/06/06/despe rately-seeking-sources-the-quest-for-the-originalcitation/ 
Pickett, S.T.A., Kolassa, J. and C.J. Jones. 1994. Ecological understanding: the nature of theory and the theory of nature. Academic Press, San Diego.

Rowntree, J. K., McVennon, A. and R.F. Preziosi. 2010. Plant genotype mediates the effects of nutrients on aphids. Oecologia 163: 675-679. CrossRef 